Illinois State University

ISU ReD: Research and eData

Theses and Dissertations

3-14-2017

\title{
The Influence of Corrective Exercises on Functional Movement Screen and Physical Fitness Performance in Army ROTC Cadets
}

Marissa Jae Basar

Illinois State University, mjbasar@ilstu.edu

Follow this and additional works at: https://ir.library.illinoisstate.edu/etd

Part of the Kinesiology Commons

\section{Recommended Citation}

Basar, Marissa Jae, "The Influence of Corrective Exercises on Functional Movement Screen and Physical Fitness Performance in Army ROTC Cadets" (2017). Theses and Dissertations. 652.

https://ir.library.illinoisstate.edu/etd/652

This Thesis is brought to you for free and open access by ISU ReD: Research and eData. It has been accepted for inclusion in Theses and Dissertations by an authorized administrator of ISU ReD: Research and eData. For more information, please contact ISUReD@ilstu.edu. 


\title{
THE INFLUENCE OF CORRECTIVE EXERCISES ON FUNCTIONAL MOVEMENT
}

\section{SCREEN AND PHYSICAL FITNESS PERFORMANCE IN ARMY ROTC CADETS}

\author{
Marissa J. Basar
}

\section{Pages}

Background: The Functional Movement Screen (FMS) is a screening tool specifically designed to identify limitations and irregularities between sections of the body during functional movement. The existing literature has demonstrated the FMS as an effective tool for identifying movement dysfunction; however, there is limited evidence on its' effectiveness for improving FMS scores through the use of individualized corrective exercises. Theoretically, improving functional movement may provide assistance in improving physical performance and potentially decrease occurrence of injury. Objective: To examine if individualized corrective exercises are effective in improving composite FMS scores in Reserve Officers' Training Corps (ROTC) cadets. In addition, this study aimed to correlate improvements in composite FMS scores with the ROTC cadets' physical fitness performance as established with the standard Army Physical Fitness Test (APFT). Study Design: Cluster-randomized, cohort study. Methods: Forty-four healthy, physically active ROTC cadets (age: $19.84 \pm 1.48$ years, weight: $71.75 \pm 13.52 \mathrm{~kg}$, height: $172.29 \pm 45.20 \mathrm{~cm}$ ) met all inclusion and exclusion criteria for the study. Participants were assigned into one of two groups: experimental $(n=24)$ or control $(n=20)$. Participants in the experimental group were required to complete an individualized corrective exercise program three times per week for four weeks, in conjunction with the current morning ROTC Physical Training (P.T) regime. The participants in the control group continued to participate in the standard preparation drills during morning P.T. Results: Two, Mann-Whitney U tests were 
performed to compare FMS total composite scores and APFT total composite scores performed between groups. A Pearson product-moment correlation was used to explore the relationship between FMS and APFT scores. The statistical analysis revealed a significant difference in FMS composite scores between the control and intervention groups following the 4-week intervention $(\mathrm{U}=87, \mathrm{z}=-3.83, \mathrm{p}=0.001$, Effect size $=1.33,95 \%$ CI: 0.69-1.98), while analysis revealed no significant difference in APFT scores between the two groups $(\mathrm{U}=237.5, \mathrm{z}=-0.33, \mathrm{p}=0.74)$. Lastly, a non-significant, correlation between the FMS and APFT scores $(\mathrm{r}=0.25, \mathrm{p}=0.10)$. Conclusion: The results of this study demonstrated individualized corrective exercises improved FMS scores, but fail to improve physical fitness performance, as measured by the APFT. The results indicated a weak correlation between FMS and physical fitness performance. KEYWORDS: Movement Dysfunction, Physical Performance, Athletic Performance 
THE INFLUENCE OF CORRECTIVE EXERCISES ON FUNCTIONAL MOVEMENT

SCREEN AND PHYSICAL FITNESS PERFORMANCE IN ARMY ROTC CADETS

MARISSA J. BASAR

A Thesis Submitted in Partial

Fulfillment of the Requirements

for the Degree of

MASTER OF SCIENCE

School of Kinesiology and Recreation

ILLINOIS STATE UNIVERSITY

2017 
Copyright 2017 Marissa J. Basar 
THE INFLUENCE OF CORRECTIVE EXERCISES ON FUNCTIONAL MOVEMENT

SCREEN AND PHYSICAL FITNESS PERFORMANCE IN ARMY ROTC CADETS

MARISSA J. BASAR

COMMITTEE MEMBERS:

Justin Stanek, Chair

Rebecca Begalle

Daniel Dodd 


\section{ACKNOWLEDGMENTS}

I would first like to thank my thesis advisor Dr. Justin Stanek, Director of Undergraduate Athletic Training at Illinois State University. The door to your office was always open whenever I ran into a trouble point or had a question about my research or writing. He consistently allowed this paper to be my own work, but steered me in the right the direction whenever he thought I needed it. To the members of the committee of this work, thank you for devoting your time to this body of research, the insightful feedback, and providing answers to my numerous questions. My success would not have been possible without your guidance.

I would also like to thank the Illinois State University Reserve Officers' Training Corps Cadre and cadets for devoting your time and participation into this body of research.

Finally, I must express my very profound gratitude to my parents and to my friends for providing me with unfailing support and continuous encouragement throughout my years of study and through the process of researching and writing this thesis. This accomplishment would not have been possible without them. Thank you. 


\section{CONTENTS}

Page

ACKNOWLEDGMENTS $\quad$ i

CONTENTS

TABLES $\quad$ V

FIGURES vi

CHAPTER I: INTRODCUTION

$\begin{array}{ll}\text { Purpose of the study } & 2\end{array}$

Hypothesis 3

CHAPTER II: LITERATURE REVIEW

Army Physical Fitness Test 5

$\begin{array}{ll}\text { Historical Development and Influences } & 6\end{array}$

Functional Movement Screen $\quad 9$

Components of the Functional Movement Screen 10

$\begin{array}{ll}\text { Existing Literature } & 15\end{array}$

Normative Value and Predictive Validity 15

$\begin{array}{ll}\text { Reliability } & 17\end{array}$

Relationship with Physical Performance 19

$\begin{array}{ll}\text { Modifiability } & 22\end{array}$

$\begin{array}{ll}\text { Conclusion } & 26\end{array}$

CHAPTER III: METHODS 27

$\begin{array}{ll}\text { Study Design } & 27\end{array}$

$\begin{array}{ll}\text { Participants } & 27\end{array}$ 
$\begin{array}{ll}\text { Instrumentation } & 28\end{array}$

$\begin{array}{ll}\text { Procedure } & 29\end{array}$

$\begin{array}{lr}\text { Functional Movement Screen } & 30\end{array}$

Army Physical Fitness Test 32

Intervention $\quad 33$

$\begin{array}{ll}\text { Data Reduction } & 34\end{array}$

Statistical Analysis $\quad 34$

CHAPTER IV: RESULTS 36

$\begin{array}{ll}\text { Results } & 36\end{array}$

Discussion $\quad 36$

$\begin{array}{ll}\text { Limitations } & 42\end{array}$

CHAPTER V: CONCUSLION 43

Conclusion and Implications 43

Practical Application $\quad 43$

$\begin{array}{ll}\text { REFERENCES } & 47\end{array}$

APPENDIX A: FMS SCORING CRITERIA

APPENDIX B: FMS VERBAL INSTRUCTIONS 53 


\section{TABLES}

$\begin{array}{lll}\text { Table Page } & \text { Pas }\end{array}$

1. Descriptive Statistics: Participant Demographics 45

2. Descriptive Statistics: Pre and Post FMS scores 45

3. Descriptive Statistics: Pre and Post APFT scores 45 


\section{FIGURES}

Figure $\quad$ Page

1. Correlated Relationship between the FMS and APFT 46

2. Participant Apparel: Improved Physical Fitness Uniform 46 


\section{CHAPTER I: INTRODUCTION}

Functional movement is defined as "the ability to perform locomotor, manipulative, and stabilizing actions while maintaining control along the kinetic chain. ${ }^{, 1,2}$ Dysfunction is a term related to movement, as it is to be associated when an individual is unable to perform a functional movement pattern correctly. Whether dysfunction is a result from imbalances in muscular strength, deficits in neuromuscular control, or presence of asymmetries, it can ultimately compromise an individual's physical performance. ${ }^{1,3-6}$ When an individual possess movement dysfunction, their quality of life and ability to physically perform becomes impaired as they unconsciously are sacrificing efficient for inefficient movements in order to perform at high levels.

Similar to the athletic population, the physical fitness of a soldier is a critical element within the military lifestyle. Soldiers are required to perform numerous tasks involving an extensive degree of physical effort throughout their military career. ${ }^{7-10}$ While soldiers demonstrate to have a significant amount of both strength and endurance, they often are involuntarily forfeiting efficient movements to perform high level activities specific to their military obligations. Consequently, they are adding fitness to their dysfunction. Cook et al. ${ }^{3}$ suggest individuals performing high levels of activities typically are unable to perform simple movements and often are using compensatory movement patterns during their activities. Therefore, identifying ones' ability to perform efficient functional movement may provide advance assistance in monitoring physical performance and potentially to decrease the occurrence of injury. 
The Functional Movement Screen (FMS) has recently been utilized to investigate the fundamental movement patterns of individuals. ${ }^{1,3-5,11-17}$ This examination is a ranking and grading system that assesses the quality of fundamental movement patterns, as well as identifying an individual's limitation or asymmetries along the kinetic chain. The FMS consists of seven fundamental movement tests and three clearing tests requiring mobility, stability, and balance. Each test is scored on a scale of 0 to 3 based on execution of the specific movement patterns. The maximum achieved score can be $21^{1,3-5,8,11-14,16,18-23}$

The FMS is not a diagnostic tool; it is a screening tool specifically designed to identify limitations and irregularities between sections of the body during movement patterns. Good inter-rater and intra-rater reliability have been demonstrated previously. ${ }^{12,20,24-28}$ Current literature acknowledges a relationship with injury risk and demonstrates that these tests help identify strengths and weaknesses within movement patterns. ${ }^{1,3-5}$ However, there is a limited literature that examines the cause-effect relationship between the FMS and performance. Furthermore, previous investigations have not studied the effectiveness of individualized corrective exercise programs at improving FMS scores. The success of the FMS suggests for the necessity to implement corrective exercises to improve dysfunction. ${ }^{12,15,18,23,29}$ One objective regarding the FMS is to identify movement pattern limitation so professionals can prescribe corrective exercises to normalize movement before increasing physical fitness demands in the active population.

\section{Purpose of Study}

The purpose of this investigation is to examine if an intervention program consisting of individualized corrective exercise is effective in improving basic functional movements as established by the Functional Movement Screen (FMS) in Reserve Officers' Training Corps 
(ROTC) cadets. In addition, this study sought to correlate FMS scores with the ROTC cadets' physical fitness performance as established with the standard Army Physical Fitness Test (APFT).

\section{Hypothesis}

We hypothesized that the FMS composite scores would improve after a 4-week intervention program of individualized corrective exercises. In addition, we hypothesized that improvements in the FMS would correlate with improvements in the APFT scores. Based on this additional hypothesis, we further hypothesized the APFT composite score would improve after a 4-week intervention program. 


\section{CHAPTER II: LITERATURE REVIEW}

The Functional Movement Screen research has continued to increase; therefore, the focus is to no longer identify an individual's limitations but to correct the recognized dysfunction. By correcting an individual's dysfunction in order to become an efficient mover, it is theoretically possible for an individual's physical fitness performance to improve as well. The purpose of this study was to examine the effectiveness of corrective exercises at improving functional movement and physical performance.

The aim of this review is to expand on the concept of fundamental movement; therefore, this review will highlight the existing literature on the Functional Movement Screen (FMS) and further discuss its relationship with physical performance, as well as the current literature regarding corrective exercises contribution to improving fundamental movement. In addition, this review will illustrate each of the specific functional movements that compose the FMS and provide important concepts regarding each of these movements. Understanding each of the basic fundamental movement that composes the FMS emphasizes the reasoning to create individualized training program that focuses on changing or modifying movement patterns.

Furthermore, physical performance can be measured in numerous ways however within this current study the physical performance variable is represented by the U.S. Army's standardized Army Physical Fitness Test (APFT). This review will begin by providing insight on this specific variable; this portion of this review will describe a brief history and influential development of what is recognized as the current physical fitness performance testing. 


\section{Army Physical Fitness Test}

Many resources have established the need for both cardiovascular and muscular strength and endurance to be able to perform specific military tasks successfully., ${ }^{7,9,10,30}$ Soldiers are required to be physically fit in order to be able to perform war time duties therefore, the importance of objective measurements of a soldier's physical capacity has constantly been an important concept for the US Army. Currently, the Army only has one standardized measurement to evaluate the physical capabilities for soldiers across the service. ${ }^{7,8,31}$

The current standardized measurement to evaluate the physical capabilities for soldiers across the service is recognized as the Army Physical Fitness Test (APFT). The APFT consists of three timed events: two minute push-ups, two minute sit-ups, and a timed two mile run. The use of the push-up event is to assess the muscular endurance of a soldier's chest, shoulder, and triceps. The use of the sit-up event is to assess the muscular endurance of a soldier's abdominal and hip-flexors (psoas major and iliacus). The use the two-mile run is to assess a soldier's aerobic fitness and lower extremity muscular endurance. Each of the three standard events is scored on a scale of 0 to 100 . An overall score is determined by adding up the three event scores; thus the maximum achieved score is 300 points. The points achieved for each event determines one of two outcomes: pass or fail. To achieve a passing score, one must achieve at least 60 points for each event, resulting in an overall score of 180 points. Scoring is based on sex, age category, and number of repetitions performed or run time. ${ }^{7,9,10,30,31}$ Score tables are found on the Department of the Army form 705..$^{7,9,10,30,31}$ The personnel recommended for administering the APFT include: an Officer in Charge (OIC) and/or Non-commission Officer in Charge (NCOIC), event supervisor(s), one event scorer for every eight soldiers being tested, a timer and back up timer, and required support personnel. Of the listed personnel recommended, a minimum of four people 
are required to administer an APFT: OIC or NCOIC, an event supervisor(s), an event scorer(s), and support personnel. ${ }^{7,9,10,31}$

\section{Historical Development and Influences}

The process of developing this standardized form of objective performance testing on U.S. Army soldiers has a fluctuating history and has adapted in every aspect. The first Army fitness test for all soldiers was referred to as "Individual Efficiency Tests," as it was developed in 1920 following World War I. ${ }^{7}$ The Individual Efficiency Tests originally included six events: 100-yard run, running broad jump, wall climb, hand grenade throw, and obstacle course. From early 1920 to 1940s, the Army frequently published the basic Field Manuals (FM) which incorporated various aspects of physical training. It was not until March 1941 when the Army published the first Field Manual dedicated exclusively to physical training, Field Manual (FM) 21-20. Unlike the Individual Efficiency Tests, the original FM 21-20 consisted of four tests: 100yard dash, running high jump, running broad jump, and push-up from ground. The Individual Efficiency Tests differed in events and specific passing standards then the FM 21-20, as the FM 21-20 tests and standards were implemented to measure fitness improvement among soldiers and to determine the effectiveness of the training program. ${ }^{7}$ The differences between the Individual Efficiency Test and the FM 21-20 are one of many examples of the adaption and revisions of the U.S. Army performance testing.

As the sole source for physical training the Field Manual (FM) 21-20 continue to undergo multiple revisions of physical events, standards, and identified titles. ${ }^{7}$ For example, the 1957 version of FM 20-21 recognized the measured events to be called "Physical Fitness Tests" and established the requirement for the events to be administered in a specific order. Along with the additional revisions the Army also introduced the "Physical Achievement Test," which was a 
functional "combat readiness" test. While in 1961, the Physical Fitness Tests and Physical Achievement Tests were replaced with the "Physical Combat Proficiency Test." By 1969, the fifth revision of FM 21-20 was published and called the physical test to be the "Physical Combat Proficiency Test." In 1973, the Army suffered what is to be acknowledged as test proliferation. During this time, the 1973 FM 21-20 edition identified to have at least seven different fitness assessments to become a part of the "Army Physical Fitness Evaluation.",

The current physical fitness testing has remained the same since the 1980 FM 21-20 edition which was originally titled Army Physical Readiness Training (APFT). It was this edition that introduced the three tested events, which are still in use today. ${ }^{7,31}$ Although the current physical fitness testing has remanded the same since the 1980 publication, it has been influenced by several pervious additions. For example, although the point system has changed, it was the 1944 War Department Pamphlet 21-9 introduced the use of a point system to establish a normative scale. ${ }^{7}$

The Army Physical Fitness Test has also been influenced by pervious addition regarding a soldier's gender and age. For all the three events, body composition is influenced by age and gender, which in tum affects one's ability to perform, therefore, age and gender are considered in the scoring of the events. The significance of age and gender was not always considered, as the (1946) FM 21-20 edition first introduce age adjustment standards. According to this edition, the age adjustment required for scores to drop one point for each year a solider was 30 or more years of age. Additional significant edition aspects to the US Army standards of physical testing occurred in 1963. In 1963, the Department of Army Pamphlet (DA Pam) 21-1 published the "Minimum Physical Fitness test-Males" and the Department of the Army Pamphlet 21-2 published the "Army minimum Physical Fitness Test-Female." Due to these pamphlets, for the 
first time, all male and female personnel less than 40 years of age were required to be tested periodically for physical fitness. Twice yearly testing was mandated for all active Army units and minimum passing standards were specified. Along with the gender and age consideration, another factor that led to the selection of three events for what is now the current Army Physical Fitness Test (APFT) was that the APFT did not require any equipment. The first factor was influenced by the 1944 War Department Pamphlet 21-9, as its criteria encompassed minimal use of equipment, easy administration, and safety. ${ }^{7}$

Although performance testing of U.S. Army soldiers has reformed overtime, the basic reasons for using this performance assessment has remained the same. For the U.S. Army, the physical fitness performance testing provides soldiers with motivation during Physical Training (P.T.) or Basic Combat Training (BCT), aids as an evaluation of physical capacity of soldiers, and examines the effectiveness of physical training programs. ${ }^{7-10}$ The Army Physical Fitness Test ensures the maintenance of a base level physical fitness essential for every soldier. Although the APFT has been well established, it fails to provide the adequate information regarding both a soldier's battlefield physical readiness and quality of life.

Consider the following example of two soldiers who both have completed the sit-up event within the following standards of the APFT. One soldier who received an above average score on the number of sit-ups performed but still performed inefficiently by compensating and initiating the movement with the upper body and cervical spine instead to the trunk. Now, compare this solder to another solider who also received an above average on the number of situps but performed very efficiently and did not utilize compensate movements to perform the situp. Between these two soldiers, both would each be deemed above average and pass their APFT without noting their individual movement inefficiencies. Similar to other well established 
performance screenings, the military's performance assessment procedures fails to provide adequate baseline information regarding an individual's preparedness for activity and can often exclude or penalizes the individual from participation. The FMS has been a common tool to connect the dots between a screening tool and performance testing by providing qualitative information of an individual's movement quality.

\section{Functional Movement Screen}

The FMS was originally developed by Gray Cook and Lee Burton, to help assess functional movement insufficiencies and asymmetries within the kinetic chain in the healthy population. ${ }^{12,20,24,32}$ Fundamental movement can be commonly defined as the ability to produce and maintain balance between mobility and stability along the kinetic chain while simultaneously performing movement patterns accurately and efficiently. ${ }^{3,4,18,33}$ The FMS evaluates functional performance as it requires muscle strength, flexibility, range of motion, coordination, balance, and proprioception in order to successfully complete seven fundamental movement patterns. ${ }^{3,4,11,20,24}$ Each of the FMS tests and their scoring criteria has been well described in

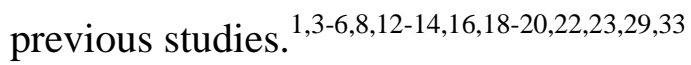

The seven tests that comprise the FMS include the overhead deep squat, hurdle step, inline lunge, active straight leg raise, shoulder mobility, trunk stability push-up, and rotary stability. Five of the seven tests allow for right-left asymmetry to be detected as these five tests required to be scored independently from the both the right and left side of the body. Each test is scored on a scale from 0 to 3; 0 to be the worst and 3 being the best score possible. Each test has specific criteria outlined to differentiate among the four possible scores. Any pain identified during the movement or clearing tests automatically results in a score of 0 . A score of 1 indicates the individual is unable to complete the movement pattern or unable to assume the position to 
perform the movement; a score of 2 indicates the individual is able to complete the movement but must compensate in some way to perform the movement; a score of 3 indicates the individual is able to perform the movement without any compensation.

In addition to the seven FMS test, there are three clearing assessments. The three clearing assessments accompany three of the seven FMS movement patterns. The three clearing assessments include active impingement (associated with shoulder mobility), trunk extension (associated with trunk stability push-up), and trunk flexion (associated with rotatory stability). The three clearing assessments are part of the standard FMS procedure to assess for pain and injury. They are to be performed during the associated test and graded as a positive or negative. A positive grade indicates pain to be reported, thereby providing a score of 0 for the associated FMS movement pattern. A negative grade indicates no pain being reported. ${ }^{1,3-}$ $5,8,11,12,14,18,20,23,24,29,33,34$

\section{Components of Functional Movement Screen}

Practitioners identify the limitations and the deficiencies in strength, mobility, stability, and flexibility through the information gathered from the individual FMS tasks. The seven tests that comprise the FMS can be categorized by the noticeable demands placed on certain regions of the body: lower extremity and upper extremity. The lower extremity patterns consist of the deep squat (DS), hurdle step (HS), in-line lunge (ILL), and active straight leg raise (ASLR). While the upper extremity and trunk patterns consist of shoulder mobility (SM), trunk stability push-up (TSPU), and rotatory stability (RS). ${ }^{24}$ Although the literature commonly recognizes this classification, these FMS tests are also clinically categorized. Therefore, instead of categorizing into upper and lower extremity, the individual tests can be one of the three movement categories: mobility, stability, or advanced movement. 
Acknowledging the clinical categorization of movement is important; however, it is essential to understand the hierarchy within this categorization. Between the three categories, only mobility and stability are considered to be primary movement patterns. Four of the seven tests (ASLR, SM, TSPU, and RS) within the FMS are recognized as primitive or fundamental movement patterns, while the remaining three tests (DS, HS, and ILL) are described as advance movement, which can also be referred to as "higher levels" of movement. Within this categorization hierarchy, primitive movement patterns take precedent over advance movement, as problems demonstrated within any of the four primitive tests may display compensation in the remaining three advance movement tests. ${ }^{6}$

Although both are primitive movements, mobility must precede stability because mobility demonstrates unrestricted freedom of movement in a "non-supportive situation.",6 Mobility is defined as the efficient movement of a joint or series of joints through a full, painfree range. ${ }^{3,4}$ Ideally mobility should come first before stability however, deficits in mobility are sometimes the only way the body can achieve some form of stability. When there is a lack of mobility to gain stability, the gained stability is ultimately not dependable. Stability is recognized as the muscular control applied on a joint to transmit force and control movement in the presence of normal flexibility and joint mobility. ${ }^{3,4,6}$

There are two FMS tests that represent the focused pattern of mobility, active straight leg raise and shoulder mobility. The ASLR pattern assesses primarily flexibility of the lower extremity. The ASLR determines active hamstring and tricep surae flexibility while simultaneously maintaining stability in the pelvis and active extension in the opposite leg. ${ }^{4,5,11,35}$ Deficiency when performing this particular test is often due to inadequate hip mobility; however, it is suggested to be more specific to the limitations enforced by the hamstrings and iliopsoas. ${ }^{4,5}$ 
The SM test is the only movement pattern that only assesses the upper extremity. The SM measures bilateral shoulder range of motion, scapular mobility, and thoracic spine extension. Performing this movement pattern involves attempting to touch their fists together behind their back, thus requiring both a combination of shoulder internal rotation with adduction and shoulder external rotation with abduction. ${ }^{4,5,11,16,23}$ Since the SM test is typically addresses the overhead athletic populations the general explanation for deficit performance is due to the increased external rotation that is increased at the expense of decreased internal rotation in result of overhead throwing. ${ }^{4,12}$ Within the literature, gender differences have been noted with males experiencing more dysfunction in comparison to females. ${ }^{12,16}$ In both Loudon et al.$^{16}$ and Schneiders et al. ${ }^{12}$ females demonstrated to be more flexible than males for both of the mobility tests.

Similar to the mobility classification, there are two FMS tests that represent the pattern of stability, also known as "motor control." The two tests that represent stability include the trunk stability push-up and the rotary stability. The TSPU involves performance of a standard push-up with hands shoulder width apart. The TSPU is a combination of core and upper extremity stability with associated Glenohuemral strength. ${ }^{5,19,35}$ The TSPU assesses trunk stability in the sagittal plane while a closed kinetic chain symmetrical upper extremity motion is performed. Performing the TSPU requires an isometric contraction to avoid spinal hyperextension during the raising phase of a push-up; therefore discrepancies can often be due to inadequate stability of the trunk and core stabilizers. ${ }^{4,5,12}$ Unlike the TSPU, the RS test includes multi-plane trunk stability with the upper and lower extremities in combined motion. The RS is a complex movement requiring proper neuromuscular coordination and energy transfer throughout several segments of the body. The enactment of this movement requires an individual to assume a quadruped 
position and attempt to touch their knee and elbow first on the same side of the body and then on the opposite side. ${ }^{23}$ Similar to the TSPU, faulty performance of the rotary stability test is due to inadequate stability of the trunk and core stabilizers; however, it is specifically attributed to poor asymmetric stability of the trunk stabilizers. ${ }^{4,5,12,17}$

For both these tests, the stability restrictions may also include isolated weakness, but generally are more complex and refers to multiple systems motor control. According to Agresta et al. ${ }^{17}$ runners with lower scores on RS were suggested to have impaired trunk, pelvis, and hip muscular control, which was then considered as the contributing factor to abnormal lower extremity mechanics. The sex differential findings are supported by various studies. ${ }^{12,19,29}$ Males have demonstrated to be significantly stronger than females; as males tend to be significantly better in performing the trunk stability push-up test. ${ }^{12,19,29}$ Schneiders et al. ${ }^{12}$ reported females to have scored the lowest on RS, thus suggesting strength demands including stability and neuromuscular control to be better in males then females. While Agresta et al. ${ }^{17}$ found no significant difference between gender in RS, it was the lowest score across all runners.

The three remaining tests that represent advanced movement include the overhead deep squat, hurdle step, and the in-line lunge. The HS and ILL were designed to challenge the body in specific positions, while the DS was designed to challenge total body mechanics. Performing the HS requires the individual to place a dowel behind their head, across the shoulders and to step over a hurdle that is placed directly in front of them. ${ }^{23}$ This particular test is intended to challenge the body's proper stride mechanics during a stepping motion. The HS requires proper coordination and stability between the lower extremity and torso during the stepping motion as well as single leg stance stability. The stepping motion in the HS requires simultaneous activation of hip flexion and external rotation. Inadequate performance potentially is due to 
deficits in stability of the stance leg or deficits in mobility of the stepping leg. ${ }^{1,3,6,29}$ During the ILL, the feet are aligned and the dowel is in contact with the head, back, and sacrum as the individual performs a split squat. The body position for the ILL focuses on the stress during rotational, decelerating, and lateral type movements produced in exercises, activity, or sport. The ILL moves the lower extremities in a scissor style position stimulating the body's trunk and extremities to resist rotation and maintain proper alignment. The narrow base requires appropriate starting stability and continue dynamic control of the pelvis and core within an asymmetrical hip position equally sharing the load. ${ }^{36}$ This test assesses hip and ankle mobility and stability, quadriceps flexibility, and knee stability. ${ }^{35}$ Poor performance is suggested to be due to several possibilities including insufficient hip mobility in either stance leg or stepping leg, the knee or ankle of the stance leg lacks the required stability, or an imbalance in present between adductor weakness and abductor tightness in one or both hips. ${ }^{1,3,29}$

Lastly, the DS challenges total body mechanics and requires the dowel to be placed over the head with the arms outstretched and the individual to squat as low as possible. ${ }^{23}$ The DS assess bilateral, symmetrical and functional mobility of the hips, knees, and ankles as well as bilateral, symmetrical mobility of the shoulders and thoracic spine. ${ }^{1,3,35}$ Insufficient performance indicates limited mobility in the upper torso due to poor glenohumeral and thoracic spine mobility or limited mobility in the lower extremity including deficient closed-kinetic chain dorsiflexion of the ankles or deficient flexion of the hips may also cause flawed test performance. ${ }^{1,3}$ The DS is a movement needed in most athletic events. Four different studies all suggest the results of a DS to be successful in identifying individuals at an elevated risk for injury as it integrates efficiency of total body movement patterns. . $^{3,11,19,37}$ 


\section{Existing Literature}

Understanding each of the basic fundamental movements that compose the FMS provides an opportunity to understand why this assessment tool has gained popularity clinically. The FMS has gained support as a way to efficiently screen for fundamental movement ability as well as providing a logical approach to improve limited movement patterns. This tool has gained in popularity clinically and research has emerged that adds to the understanding of its usefulness.

\section{Normative Values and Predictive Validity}

Since the FMS is an assessment tool that assesses movement patterns in a practical and dynamic method, it has been utilized by a variety of professionals within and outside of the healthcare realm. The FMS has gained in popularity amongst Physical Therapists, Athletic Trainers, strength and conditioning coaches, personal trainers, and coaching staff. ${ }^{34}$ The FMS has been indicated to be fairly generalizable as it has been used to compare individuals throughout a variety of populations. ${ }^{12,32}$ The FMS has been performed on the active youth and adult populations including, recreational to professional athletes, firefighters, and military service members. ${ }^{11-13,16,17,19,37,38}$

Preliminary research indicates slight difference between the comprehensive FMS scores. For example, as in Loudon et al. ${ }^{16}$ the FMS composite score for young runners was slightly lower than a study conducted by Kiesel et al. ${ }^{11}$ who tested on professional football players. In Kiesel et al. ${ }^{11}$, the identified mean score for all football players was $16.9 \pm 3.0$, while the mean score for those who suffered an injury was $14.3 \pm 2.3$ yet $17.4 \pm 3.1$ for those who were not injured. ${ }^{11}$ The results from this study showed to be higher in scores comparison to Loudon et al. ${ }^{16}$ Between these two studies, the difference could be based on the dissimilarity of the population, as professional football players' scores may be better than the average athlete due to different 
training regimens. On the contrary, the scores demonstrated in Loudon et al. ${ }^{16}$ were higher than the values found in the study by Schneiders et al. ${ }^{12}$ who investigated an active, healthy population. This study included two hundred and nine participants both male and female and the mean composite FMS scores was 15.7 with $95 \%$ confidence interval between 15.4 and 15.9 . Interestingly, the mean composite score in Schneiders et al. ${ }^{12}$ was slightly higher than Agresta et al. ${ }^{17}$ finding of $13.13 \pm 1.7$, who tested a running population, specifically healthy, distance runners.

The FMS has been used to compare individuals throughout a variety of mixed populations and literature has not found or observed any significant differences to exist between males and females in overall FMS scores, only individual FMS scores. ${ }^{12,17,39}$ Although the FMS is not intended to diagnose injury, the FMS has demonstrated an increased probability of being injured. ${ }^{11,12,16,18,19,21,39-41}$ For example, in Schneirder et al. ${ }^{12} 31 \%$ of the two hundred and nine participants who had a score of 14 or less were acknowledged to be at potential risk of injury. A substantial amount of the research utilizes this composite score of 14 to be the "cut off" value and for individuals who demonstrate less than or equal to 14 are consider to be at a greater

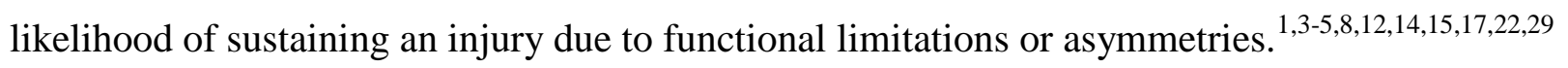

Even though the literature considers 14 to indicate an increased risk of injury that does not necessary mean that an increase FMS score will reduce one's risk of injury. Therefore, based on established normative values, it can be assumed individuals with higher FMS scores can demonstrate appropriate, symmetrical movements, better balance and posture, and overall better performance; however this does not imply those individuals are at a decrease risk to sustain an injury. With the popularity of the FMS, clinician and researchers are concerned with the reliability and validity of the screen. 


\section{Reliability}

The FMS has been shown to be a reliable method for screening the physically active.

Multiple investigations have evaluated and supported the intra-rater and inter-rater reliability of the FMS. ${ }^{12,20,24-28}$ Multiple raters testing a single trail, also known as inter-rater reliability has been conducted by several investigations including but not limiting to Gulgin et al. ${ }^{20}$ and Shultz et al. ${ }^{27}$ For several studies, the ICC values for interrater reliability were generally high. ${ }^{12,20,24-26}$ For example, in Gulgin et al. ${ }^{20}$ the inter-rater reliability of the FMS scoring was between three trained novices' raters and one expert rater. In this study despite the levels of experience of the raters, the total FMS scores revealed to be similar between the four raters and the inter-rater reliability (ICC $=0.882$ ) demonstrated good to excellent correlation for the majority of the individual FMS tests. In Shultz et al. ${ }^{27}$ the test-retest reliability of the FMS was assessed to determine the inter-rater reliability between six raters. In Shultz et al. ${ }^{27}$ the FMS was founded to be a reliable test when used by the same rater. However, in contrast to the results in Gulgin et al. ${ }^{20}$ the results indicated there to be poor inter-rater reliability when comparing FMS scores across raters. ${ }^{27}$ According to this study, raters with less experience (less than 1 year) had fair reliability (ICC $=0.44$ ) and the rater with more experience ( 2 years or more) had poor reliability $(\mathrm{ICC}=0.1777)$.

In addition to establishing normative data, the study conducted by Schneiders et al. ${ }^{12}$ found the inter-reliability for the composite FMS score to have excellent reliability (ICC $=0.971)$. The inter-reliability for individual test components demonstrated to be substantial to excellent. The results from this study allowed for different individuals to be involved in the data collection when the FMS is administered to large groups. However, a limitation of this study is it did not report the level of clinical experienced of the raters, only that they were experienced. 
Onate et al. ${ }^{24}$ was one of the first studies to investigate the inter-rater reliability between noncertified novice raters and a certified FMS experienced rater. In this particular study, the novice raters were described to have scored the FMS and read the FMS manual one time, but also to have never scored the FMS during any type of testing trails. In Shultz et al. ${ }^{27}$ five of the six raters were defined to be trained by a certified FMS administrator and one undergraduate student was self-taught and demonstrated their ability to a certified FMS instructor. Reliable FMS scoring can be achieved regardless of the quantity of raters (single vs. multiple) and the rater's training in FMS as supported by several investigations. ${ }^{20,24-26,28}$ Onate et al. ${ }^{24}$, Teyhen et al. $^{26}$, and Smith et al. ${ }^{25}$ assessed inter-rater reliability of FMS among raters of different levels of training. Between each of the studies, all of them reported to have good to excellent intra-rater $(\mathrm{ICC}=0.74-0.92)$ and inter-rater reliability $(\mathrm{ICC}=0.76-0.98)$ of FMS composite scores. $^{27,28}$

Furthermore, reliable data can be achieved regardless of scoring in real-time or use of video recording. ${ }^{12,20,24,25,27}$ Schneiders et al. ${ }^{12}$, Onate et al. ${ }^{24}$, Teyhen et al. ${ }^{26}$, and Smith et al. ${ }^{25}$ assessed FMS scoring using real-time, while Guglin et al. ${ }^{20}$ used video recording. Real-time measurement differs in comparison to video analysis, as video analysis provides the rater the opportunities to replay any of the performed FMS movement patterns. In Gulgin et al. ${ }^{20}$ raters were allowed to replay the video with no restriction on how many times they could view the recorded movements. Interestingly, this study also reported for the recorded movements to be played at normal speed and did not allow slow motion views, in attempt to replicate real time scoring. Rater observation position is suggested to play a key role in reliability as different positions during FMS scoring could change the final score recorded. ${ }^{24}$ While Onate el al. ${ }^{24}$ reported high reliability across intersession and inter-rater assessments for total and each task of the FMS, this study recognized caution with the HS movement pattern; as this was the only 
movement pattern demonstrated to have poor inter-rater reliability. Poor inter-rater reliability of HS was suggested to be due to rater observation location real time assessment of the HS requires the simulations 3-dimensional assessment of hip flexion and external rotation. During real time measurement raters can be placed in different positions as the raters attempted to stand with similar view of the subject (i.e. front, side, etc). In Shultz et al. ${ }^{27}$ the raters assessed the test-retest and inter-rater reliability of the FMS and compared the scoring by one rater during a live session and the same session on video. The results founded good reliability for the test-retest and excellent reliability for the live-versus-video sessions. The good test-retest and high live-versus video session reliability show that the FMS is a usable tool within one rater. The FMS inter-rater reliability may be improved with better training for the rater.

The volume of literature supports the efficacy, accuracy, and reliability of the Functional Movement Screen. ${ }^{11,12,16,18,20,24,26,27}$ However, there are limited studies in existence that have yet to examine the difference in physical performance.

\section{Relationship with Physical Performance}

Ideally correcting movement alignment, quality, and symmetry should realistically correlate with enhanced movement and athletic performance. ${ }^{34}$ However, there is little research that has examined or correlated the association between FMS and physical performance. ${ }^{2,33,34,42-}$ ${ }^{44}$ Throughout the surrounding evidence, it is unclear if the FMS composite scores can truly correlate with or predict athletic performance..$^{2,8,32-34,42,44}$ Some of the evidence investigating this relationship between FMS scores and performance has suggested the FMS to be weakly correlated with athletic performance ${ }^{32-34,44}$ For example, Parchmann and McBride ${ }^{44}$ investigated this relationship and reported the FMS scores to have no significant relationship to any performance variables such as sprinting, jumping, or agility performance in competitive, 
collegiate golfers. Several tests were utilized (10-meter sprint, 20-meter sprint, vertical jump, and agility t-test) in this study however, the FMS data was inadequately correlated with agility t-test time $(r=-0.15), 20-m$ sprint time $(r=20.11)$, and vertical jump $(r=0.25 .)^{44}$

Lockie et al. ${ }^{2}$ analyzed relationships in females between FMS and athletic performance as measured by flexibility of the lower extremity (sit-and-reach), linear speed (20-meter sprint), change in direction and speed (505 change-of-direction test and modified t-test), and lower limb power (vertical and broad jump tests). In this study, the composite FMS scores did not significantly correlate to the majority of the performance measurements but a small correlation between FMS scores and flexibility was demonstrated (r=0.756). Although, Lockie et al. ${ }^{2}$ demonstrated a small correlation for flexibility the overall study suggests the FMS is limited in the ability to detect movement compensation that could impact athletic performance in female athletes.

Interestingly, one study provided evidence for an indirect association between movement quality and the performance outcomes in track and field athletes. ${ }^{43}$ This study specifically observed if FMS scores were related to the season's best performance changes over one season. Across the subjects within the study, there were no significant correlations between FMS scores and seasonal performance change $(\mathrm{r}=-0.19, \mathrm{p}=0.97)$. This study reported at least one asymmetry was identified in more than $50 \%$ of the cases. In addition, the FMS scores and asymmetry presence were related to longitudinal performance outcomes in sprint, hurdle, distance, jumps, throws, or multi events. However, these results are difficult to generalize since this study was conducted on highly trained elite track and field athletes.

The relationship between FMS and athletic performance appears to not be significantly correlated with athletic performance reference standards in most studies; however, there are 
certain studies that have revealed individual components of the FMS to have correlations with performance..$^{8,32,42}$ In a study performed by Lockie et al. ${ }^{42}$ the relationship between the FMS, especially the lower extremity portions (DS, ILL, and HS) was analyzed with tests of multidirectional speed and jumping. The results indicated the DS to be significantly correlated to bilateral vertical $(\mathrm{p}=0.047)$ and bilateral standing long jump $(\mathrm{p}=0.033)$. Overall, the results of this study revealed three significant correlations, all to be positive and moderate in strength. In another study performed by Okada et al. ${ }^{33}$ a moderate, negative relationship was found between the ILL to the T-test in recreationally, active individuals ( $\mathrm{r}=-0.46)$. Okada et al. ${ }^{33}$ also found no significant relationship between FMS score, core stability or athletic performance.

Lisman et al. ${ }^{8}$ examined the association between FMS scores and Physical Fitness Test (PFT) which is the standardized test for soldiers within the Marine Corps. The PFT consisted of pull-ups till exhaustion (PUE), timed abdominal crunches (AC), and timed 3-mile run (RT). Unlike Okada et al. ${ }^{33}$ in this study the PFT performance scores and FMS test components demonstrated to be positively correlated. The results from this study revealed the PUE test was positively correlated with four of the seven FMS tests (DS, ILL, ASLR and STPU) and was the only PFT test associated with total FMS score. The RT was significantly and negatively related to the lunge, whereas AC performance was positively related to both the DS and ILL.

Although studies demonstrate to have correlations, it is difficult to generalize these results for screens to specifically identify a deficiency that could be correlated with a view to improve athletic performance. Of the current literature it is possible the components of the FMS do not capture the essential, functional movement components utilized by many athletic activities thus demonstrating the weak correlation that literature has shown. 


\section{Modifiability}

Assessing overall functional movement and understanding each of the basic fundamental movement that compose the FMS provides an opportunity to create individualized training programs that focuses on changing or modifying movement patterns. ${ }^{12}$ Studies investigating the effectiveness of the FMS to monitor training intervention have been conducted. ${ }^{35,45-47}$ Wright et al. ${ }^{46}$ performed the first controlled trail using FMS to assess movement competency in secondary school children. However, the results of this study disagreed with the assumption that the performance on the FMS can be modified, as the four week training intervention made little impact on the total FMS score. However, this study also sought to investigate the effect of the intervention program not only on the FMS, but also on flexibility, core stability, and physiological performance. Findings showed the intervention was only able to improve core stability. On the contrary, there are other studies that have shown FMS scores can be improved through training interventions. ${ }^{35,45,47}$ Cowen et al. ${ }^{35}$ examined FMS scores in active firefighters before and after a six week yoga program and found significant improvement in overall FMS scores. In another study conducted by Goss et al. ${ }^{47}$ FMS scores in a group of special operation soldiers were found to also improve in total score by an average of 2.5 points following a sixweek intervention.

In the study by Goss et al. ${ }^{47}$ the training intervention was described to be an example of physical therapy based functional training program that aided to bridge traditional clinic constructed rehabilitation and return to duty. The six-week intervention consisted of three grouped workouts, each week that targeted three different components: core strength and balance, agility, and power. Along with the three organized group workouts, participants were given individualized strength and conditioning program based on personal goals. Both Cowen et 
al. ${ }^{35}$ and Goss et al. ${ }^{47}$ reported that with intervention programs, scores on the FMS can be improved with a six-week intervention program. Although these interventions demonstrated improvement in FMS scores, the training intervention programs described can be interpreted to be physical fitness programs and not corrective exercise programs. Corrective exercise programs are essentially categorized as pre-rehabilitative exercises, not fitness programs. For the program intervention described in Goss et al. ${ }^{47}$ the biggest distinction between physical training versus corrective exercises was the intervention was reported to be 75 minutes in duration, which for most is unconventional and impractical to be categorized as pre-rehabilitative exercises.

Corrective exercises are designed to address and enhance the relationship between muscle function and fundamental movement by re-training dysfunctional movement patterns, establishing symmetrical movement, and recovering balance posture. ${ }^{3,14,15,18,29,32,47}$ Of the surrounding literature, there are four studies ${ }^{14,29,35,47}$ that have reported that with exercises programs, FMS scores can be improved with at least four to six week training programs; while only one study ${ }^{22}$ has reported FMS scores cannot be changed across a twelve week program. Alongside with previously mentioned studies ${ }^{35,47}$ above, the majority of the existing literature on the potential changes that an intervention program of corrective exercises has on FMS scores is mainly based on three other different studies. ${ }^{14,22,29}$

Similar to Cowen et al. ${ }^{35}$ and Goss et al. ${ }^{47}$ these studies differ in intervention program, participants, and overall study design. ${ }^{15}$ In Bodden et al. ${ }^{29}$ the participants were mixed martial art athletes who participated in an eight week intervention program. In Kiesel et al. ${ }^{14}$ participants were professional football players who participated in a seven week program. In Frost et al. ${ }^{22}$ participants were professional firefighters in a twelve week program. Between the three investigations, only Bodden et al. ${ }^{29}$ and Frost et al. ${ }^{22}$ included a control group, while Kiesel et 
al. ${ }^{14}$ did not. Despite the fact that Kiesel et al. ${ }^{14}$ did not include a control group this study still divided its' participants into two groups (football lineman and football non-lineman).

Intervention programs of corrective exercises that restore mechanical movement patterns have been directly linked to be the more beneficial to improve FMS scores. ${ }^{14,15,29}$ Gray Cook and his comrades developed a series of corrective exercises that are prescribed based on the level and type of faulty movement patterns achieved while performing the FMS and identified from an individual's FMS score. ${ }^{27}$ For both Bodden et al. ${ }^{29}$ and Kiesel et al ${ }^{14}$ the intervention programs were designed specifically to correct the identified movement dysfunction of each participant based on the procedure recommended by Cook. ${ }^{15}$ The intervention implanted in Bodden et al. ${ }^{29}$ was designed to focus on the weakest and asymmetrical scores, as its primary focus was on mobility patterns and secondary moved onto stability patterns when it was demonstrated to be appropriate. In Kiesel et al. ${ }^{14}$ the corrective exercises were designed to stimulate neutral core muscle activation to enhance the relationship between core muscle function and fundamental movement.

At the end of the intervention, participants in both Bodden et al. ${ }^{29}$ and Kiesel et al. ${ }^{14}$ exhibited improvement in FMS scores in comparison to baseline scores prior to the intervention. Kiesel et al. ${ }^{14}$ included a total of sixty-two NFL players to perform the FMS, however only seven of them scored greater than 14. These NFL players were then prescribed corrective exercises to address their specific imbalances. After the seven weeks, the players were retested and thirtynine of them scored greater than 14 . Results of this study reported an average increased in 3 points of FMS composite score after the 7 week program. In Bodden et al. ${ }^{29}$ twenty-five mix martial art athletes were separated into one of two groups. After eight weeks, the results revealed the intervention group improved by 2 points more in the FMS composite score (pre: 13.260 .8 ; 
post: 15.361 .4 ), whereas the control group showed no meaningful change (pre: 13.260 .8 ; post: $13.360 .9)$

For both studies an additional FMS re-test data collection was performed during the intervention programs to monitor the participants' progress. In Bodden et al. ${ }^{29}$ no change was demonstrated in the control group. This study found that there was only an increase in FMS score between week zero and week four after the intervention. The results showed there were no significant improvements for asymmetry at week four and week eight after the intervention. These results suggest corrective exercises are directly related to specific movement patterns can be successful at improving FMS scores. ${ }^{14,15,29}$

Interestingly, Frost et al. ${ }^{22}$ did not find significant differences in FMS scores when compared to a control group after an intervention program. ${ }^{15}$ In this study there were more than one intervention and the participants were assigned to one of three groups: intervention 1 , intervention 2, or control. The two intervention groups received the same amount of hours of training sessions each week; however each program differed. The first intervention group focused on whole body coordination and control during task execution, while the second intervention group focused on maximizing performance and fitness outcome alone. According to this study the decision concerning FMS exercise selection was made by coaches based on the initial screening results and the interventions were instructed by strength and conditioning professional.

Frost et al. ${ }^{22}$ reported no significant difference in movement patterns after an intervention program. This could be because the interventions conducted by Frost et al. ${ }^{22}$ emphasized improving the related task performance rather than specific movement pattern limitations. The results from Frost et al. ${ }^{22}$ support Cook $^{6}$ who believes aggressive physical training cannot 
change fundamental mobility and stability problems at an effective rate. It is believed that physical training utilized to change fundamental movements cannot be efficient without introducing a degree of compensation and decreased risk of injury.

\section{Conclusion}

In summary, there is an enormous quality of literature supporting the Functional Movement Screen, as it has been shown to be a reliable tool and when used it can be helpful to identify individuals who are more likely to become injured. While FMS is clinically beneficial, it has little clinical relevance if performance on the FMS is not modifiable. The previously mentioned studies within this review suggest that dysfunction can be improved through individualized or standardized intervention programs of corrective exercises. However, there is limited research including both a control and intervention group while implementing an intervention to improve FMS scores. Research also has shown that data obtained from both physical performance testing and FMS assessment can be used independently, yet little evidence currently exist about their potential additive effect or their association with one another following an intervention program. By correlating changes between the physical performance and FMS, literature can begin to determine if there is a link between improving FMS scores and overall athletic performance. Therefore, the aim of this study was to include a control and intervention group and examine if an intervention program consisting of individualized corrective exercise was effective at improving basic functional movements as established by the FMS. In addition, this study aimed to correlate improvement in total composite FMS scores with the physical fitness performance as established with the standard APFT. 


\section{CHAPTER III: METHODS}

\section{Study Design}

A cluster-randomized, cohort study was used to compare the influence of corrective exercises on FMS composite scores and APFT scores. For the purpose of this study the independent variable tested was the individualized corrective exercise intervention program. The dependent variables included composite FMS (0-21) and APFT (0-300) scores.

\section{Participants}

Based on a power analysis calculator with a significance level of 0.05 , an effect size of 0.5 , and a power of 0.8 , a sample size of 30 participants was recommended for this study design. A total of 50 (31 males, 19 females) ROTC cadets (age: 19.72 \pm 1.45 years, weight: $79.45 \pm 46.77$ $\mathrm{kg}$, and height $172.55 \pm 53.30 \mathrm{~cm}$ ) that were currently enrolled in a large university’s Army ROTC program volunteered to participate in the current study. Of the eligible participants, 14 were Military Science (M.S.) I's, 5 were M.S. II's, 15 were M.S. III's, and 10 were M.S. IV's. Each cadet's M.S. year referred to the cadet's year(s) in the ROTC program and generally related to their current academic year at the University (i.e. M.S. I's are predominately freshman, M.S.II's are sophomores, etc. $)^{30}$

Upon enrollment of the Army's ROTC program, each cadet is randomly assigned into a platoon; platoons are randomized by the ROTC cadre to ensure a mixture of all four M.S. levels. Therefore, for the current study a cluster randomization was utilized. Clusters were randomized according to the platoon number, as the platoons were assigned into one of two groups: experimental or control. Participants were placed into one of the two groups based on their already assigned platoon number. For the participants within the experimental group, the basic procedure is described in the "Intervention" section. Participants in the experimental group were 
required to complete an individualized corrective exercise program three times per week for four weeks, in conjunction with the current morning ROTC preparation drills and Physical Training (P.T) regime. The control group continued to participate in the standard preparation drills during morning P.T. Cadets not in the experimental group were offered the intervention after the study.

All participants were healthy, physically active individuals. Physically active was defined as at least 30 minutes of cardiovascular activity for $>3$ days per week. The exclusion criteria included (1) any report of a recent (<3 weeks) musculoskeletal injury; (2) any diagnosed neurological conditions that may affect motor performance; or (3) possessing any physical limitations or restrictions during the time of the study that would temporarily restrict completion of at least one of the three standard events of the APFT. Participants were instructed to not make any substantial changes or engage in additional physical activity aside from their current three times per week training regime performed at mandatory Physical Training (P.T.) and their personal physical regime outside of P.T. All participants completed a written informed consent prior to participation per university Institutional Review Board guidelines.

\section{Instrumentation}

Basic functional movements were measured with the Functional Movement Screen (Functional Movement Systems, Inc., Chatham, VA). The seven FMS movements and the criteria for scoring performance have been well described in previous studies. ${ }^{1,3-6,8,12-16,18-}$ 20,22,23,29,33 The FMS screening instructions and scoring procedures associated with the standardized version of the test were followed to ensure scoring accuracy and consistency. The FMS Test Kit was used to perform all FMS screenings. The FMS Test Kit includes a 2x6 inch thick board, dowel with measuring stick marks for overhead placement and measurements, red bungee cord for hurdle step measurement, and two red rods to place within the $2 \mathrm{X} 6$ in board for 
hurdle step measurement. ${ }^{1,3-5}$ Research has established the FMS as a reliable method for assessment of functional movement. ${ }^{12,20,24-28}$ FMS data collection was conducted by a Certified Athletic Trainer (ATC) that is level-1 FMS certified. Prior to data collection, the examiner participated in a pilot study screening of 10 participants, to establish intra-rater and inter-rater reliability. Inter-rater reliability ranged from 0.83 to 1.0 , intra-rater reliability ranged from 0.87 to 1.0 .

In addition to the basic functional movement measurements, physical fitness of the ROTC cadets was measured with the APFT. The APFT is the standard, required physical fitness assessment for all soldiers in the U.S. Army and entails three different events. Due to the specific guidelines required by the U.S. Army, the APFT administration followed the specific guidelines required by the U.S. Army Field Manual (FM) 7-22. ${ }^{31}$

The corrective exercise intervention was based on the FMS Pro 360 software, a subscription-based software program (Functional Movement Systems, www.functionalmovement.com). The FMS Pro 360 allows FMS certified raters to directly input an individual's FMS screening data which then is analyzed to identify limitations in the individual's mobility, motor control, stability, and advanced movements. Based on the FMS algorithm and an individual's screen the software selects specific exercises to target the particular patterns related to the identified limitations. The FMS Pro 360 contains over 500 exercises. The exercises selected are performed in the following order based on the goal of improving mobility, motor control and stability, followed by the advance movements.

\section{Procedures}

Data collection was performed for a total of eight weeks. Prior to the collection of FMS and APFT scores, all participants completed subjective participation questionnaires documenting 
demographic information and their current variety of physical fitness outside ROTC PT. All participation questionnaires, FMS measurements, and APFT measurements were obtained during two separate occasions; as all measurements were performed before and after the four week intervention program. Pre and post measurements were collected with a minimum of four weeks and maximum of six weeks apart from each other. Pre-intervention FMS and APFT data collection occurred two weeks prior to the intervention program. Post-intervention data collection occurred immediately following the four week intervention and all participants were screened within one week. The intervention program was performed three times per week for four weeks, for a total of twelve sessions. The same clinician performed all scoring and/or data collection for APFT and FMS scores, implementation of the FMS, and implementation of the intervention. All forms of data collection were performed in a controlled environment; except for one of the individual test within the APFT (2-mile run). For the 2-mile run, temperature, humidity, and wind values were collected to establish consistency in data collection. Participants wore the physical fitness uniform prescribed as a component of the Improved Physical Fitness Uniform (IPFU) in conjunction with the required clothing standard issued by Army Regulation 670-1; this included: (1) black, moisture-wicking running trunks, (2) gray, short sleeve IPFU Tshirt, (3) commercial running shoes, (4) calf-length or ankle-length, plain white or black socks with no logos, and (5) reflective belt (Figure 2). ${ }^{48}$

\section{Functional Movement Screen}

The 7 tests that comprise the FMS include: the overhead deep squat (DS), hurdle step (HS), in-line lunge (ILL), active straight leg raise (ASLR), shoulder mobility (SM), trunk stability push-up (TSPU), and rotary stability (RS). The individual FMS tests are subcategorized into one of the three categories: mobility, stability, and advanced movements. The mobility tests 
included the ASLR and SM. The stability tests included the TSPU and RS. Advanced movements included the DS, HS, and ILL. Five of the 7 tests are scored independently for the right and left sides of the body; allowing right-left asymmetries to be detected. Each of the seven tests are scored on a scale from 0 to 3; 0 being the worst score, and indicative of pain, and 3 being the best score possible. Each test has specific criteria outlined to differentiate among the four possible scores for each of the seven tests (APPENDIX A). Any pain identified during the movement or clearing tests automatically resulted in a score of 0 . A score of 1 indicated the participant was unable to complete the movement pattern or unable to assume the position to perform the movement; a score of 2 indicated the participant was able to complete the movement but must compensate in some way to perform the movement; a score of 3 indicated the participant performed without any compensation. Bilateral movements were scored individually with the lower of the two scores used towards the composite. The highest possible score is 21 for all 7 movements. ${ }^{1,3-5,11,12,14,18,23,24,29,33}$

No additional feedback or "coaching" was provided during the screening process other than the verbal instructions via a standard script (APPENDIX B). The verbal instructions were read as many times as necessary to the participant until they understood the movement and agreed to begin their first attempt. No practice trial attempts or visual demonstrations were given. After verbal instructions, participants performed three attempted repetitions for each test. The lowest of the three attempts was used for data reduction purposes as a representation of true deficits in function. The composite score was calculated as the final score of each individual functional movement added together. The asymmetrical tests were scored differently than that of the previously stated individual measurements. For composite score data recording for the asymmetrical tests the participants were allowed three attempts bilaterally and the worst 
measurement between the two sides were used for data reduction. Each individual test score was recorded as an additional data set; however, asymmetrical test scores were recorded as both left and right sided measurements. During the FMS each clearing test was graded with a positive or negative for pain. If the individual is noted to have a positive for pain the subsequent test will receive a 0.

\section{Army Physical Fitness Test}

All participants provided their most recent APFT scores during the time of the study. The APFT administration followed the specific guidelines required by the U.S. Army Field Manual (FM) 7-22. ${ }^{31}$ The APFT is required to be performed at the end of every month for ROTC cadets. The APFT is required to be performed in the specific order of timed push-ups, timed sit-ups, and 2-mile run on the same day. The push-up and sit-up events are to be performed under the time limit of two minutes. It is also required to allow a minimum of 10 minutes and a maximum of 20 minutes rest between each event. All three events were required to be completed within two hours. Prior to the start of each event, a standard script was read aloud, followed by a demonstration in which an individual demonstrates both the correct exercise and any disqualifying behaviors which would make the exercise incorrect. ${ }^{7,10,31}$ After all three events were completed; the designated scorers compared the recorded scores for each individual to the Physical Fitness Standard Tables for each event. Each test is scored on a scale of 0 to 100 points. Using the standard table, scoring is based on gender, age category, and the number of repetitions or run time successfully accomplished. Although scores vary based on gender and age category, a minimum score of 60 points for each test is required to pass resulting in a minimum score of 180 out of $300 .^{30,31}$ 
Administration of the APFT for the study was performed by the ROTC cadre (Lieutenant Colonel, Captain, Master Sergeant, and Sergeant First Class) and M.S. level IV's. To confirm all cadets completed the APFT, participants were divided by M.S. level and assigned to one of two days during the scheduled week of testing; M.S. level I's and III's were scheduled for one day, while the M.S. level II's and IV's were scheduled on another day. The Lieutenant Colonel, Captain, Master Sergeant, and Sergeant First Class administered the APFT for the M.S. level III's and IV's. The Lieutenant Colonel, Captain, Sergeant First Class and seven M.S. level IV's administered the APFT for the lower ranked cadets (M.S. level I's and II's).

\section{Intervention}

The intervention program of corrective exercises was performed prior to the standard preparation drills at the beginning of the morning P.T. Once the intervention program was completed, the participants returned to their typical P.T. regime. Upon the completion and recording of the baseline measurements, the researcher directly entered each participant's (within the experimental group) FMS screening data into the FMS Pro 360 account; which then identified limitations specific to each participant. Based on the FMS algorithm and the individual's screen, the software selected corrective exercises to create a custom individualized intervention program for each participant. The corrective exercises included in the programs focused on basic level with an emphasis on proper form for all movement patterns. Participants were provided an electronic and printed copy of their intervention program. Each individual intervention program consisted of approximately five to ten corrective exercises. For some of the intervention programs the use of specific equipment was required. To ensure the necessary equipment was available during the morning P.T. sessions, the FMS Pro360 software allows the clinician to select equipment available. For this study the equipment selected was the use of the 
floor, a foam roller, a dowel rod, a towel roll, and/or wall. The corrective exercises took approximately 10 to 15 minutes to perform and were performed under the supervision of an Athletic Trainer. Supervision of the intervention was required to provide further instructions on how to use the programs and answer any questions related to the specific corrective exercise program. Attendance was recorded at each P.T session to maintain compliance. Any participant who missed six or more P.T. sessions during the duration of the intervention program was excluded from the study.

\section{Data Reduction}

All raw data was recorded during measurements. Mean scores were used for each dependent variable based on previously stated criteria. The FMS and APFT scores for individual tests and composite scores were calculated and recorded into a Microsoft Excel (Microsoft, Redmond, WA) spreadsheet. In addition, based on the composite APFT score, each participant was documented in one of two categories: pass or fail. Scores were reported and analyzed in several ways to determine the efficacy of the intervention programs. Change scores were calculated for each participant by subtracting the pre-intervention from the post-intervention measurement.

\section{Statistical Analysis}

Descriptive statistics, including means and standard deviations are summarized for participants' demographic data. For the non-parametric continuous variables, two Mann-Whitney U tests were performed to compare changes between pre and post measurements for each of the dependent variables. Change scores for both dependent variables were analyzed at post-testing between groups. One Mann-Whitney U test was conducted to compare composite FMS scores, while another was conducted to compare APFT scores. In addition, a Pearson product moment 
correlation was performed to examine the relationship between the FMS total composite scores and APFT total composite scores. A value of $\mathrm{p} \leq 0.05$ was used to determine statistical significance for all analyses a priori. The SPSS statistical package (IBM SPSS Statistics for Windows, version 21.0; IBM Corp, Armonk, NY) was used to analyze significance for all variables. 


\section{CHAPTER IV: RESULTS}

\section{Results}

A total of 50 ROTC cadets were recruited for the current study. At the conclusion of the study 44 (27 males, 18 females) ROTC cadets (age: $19.84 \pm 1.48$ years, weight: $71.75 \pm 13.52 \mathrm{~kg}$, height: $172.29 \pm 45.20 \mathrm{~cm}$ ) met all inclusion and exclusion criteria and their data was used for analysis. Descriptive statistics of demographic data are presented in Table 1. Twenty-four participants were randomized to the intervention group and 20 were randomized in the control group. Over the course of the study, 6 participants were lost due to attendance $(n=2)$, a musculoskeletal injury $(n=1)$, or dependent measurements were absent $(n=3)$.

Preliminarily testing showed FMS and APFT scores were similar between groups at baseline, indicating randomization was successful in creating two equal groups. Descriptive statistics for FMS and APFT scores can be found in Tables 2 and 3. A Mann-Whitney U test revealed a significant difference in the FMS change scores between the control and intervention groups following the intervention $(\mathrm{U}=71, \mathrm{z}=-4.07, \mathrm{p}=0.0001$, Effect size $=1.42,95 \%$ CI: 0.76 2.09.) A second Mann-Whitney $U$ test revealed no significant difference in APFT change scores between the two groups following the intervention $(\mathrm{U}=223.5, \mathrm{z}=-0.389, \mathrm{p}=0.697)$. A Pearson product-moment correlation was used to explore the relationship between FMS and APFT scores prior to the intervention. Results showed a non-significant, correlation between the APFT and FMS composite scores $(\mathrm{r}=0.20, \mathrm{p}=0.19)$ (Figure 1).

\section{Discussion}

While the FMS is clinically beneficial, there is little clinical application if FMS performance cannot be modified through corrective exercise. Ideally, when limitations or asymmetries are identified, corrective exercises can be prescribed to retrain the dysfunctional 
patterns identified and reestablish normal movement. The main purpose of this study was to examine the effectiveness of a four week, individualized corrective exercise program on FMS scores in ROTC cadets. Our results showed a 1.79 increase in FMS composite scores. The results of this study suggest an individualized corrective exercise program can statistically significantly improve scores on the Functional Movement Screen. A positive change in a composite score can be interpreted to be clinically meaningful based on the strong effect size. While this change is clinically meaningful, our sample of cadets all performed above the previously established injury risk threshold of a composite FMS score of 14. Regardless, improvements indicated by a higher score in comparison to baseline suggest the individual may have reduced dysfunction and functional imbalances along with enhanced general motor control.

The majority of the existing literature on the potential changes that an intervention program has on FMS scores has reported to be successful but, mainly is based on five different studies. ${ }^{14,15,22,29,47}$ Four of those studies have reported that with intervention programs, FMS scores can be improved with at least four to six week training programs ${ }^{14,29,35,47}$; while only one study reported FMS scores cannot be changed across a twelve week program. ${ }^{22}$ It is difficult to compare the difference established in the current study with pervious literature as only two studies included a control and intervention group. ${ }^{22,29}$ The findings between these two studies are conflicting and only one shares similar results to the current study. ${ }^{29}$

Within the current study, the mean change in FMS scores for the intervention group was 1.79 with nearly no change in the control group. These results compared with the mean change scores of mix martial art athletes, who displayed a mean change of 2.1 at the end of an eight week intervention. ${ }^{29}$ Between both studies, improvements in FMS scores were demonstrated as a result of an intervention program composed of corrective exercise. It is possible the difference 
in the mean change score could be due to the differences between the populations studied. Interestingly, Bodden et al. ${ }^{29}$ included two periods of measurements (weeks 4 and 8 ) to monitor progress, however the results revealed a four week intervention program was successful at significantly improving FMS scores and there was no significant improvements between the two measurement periods of four and eight weeks. Based on these results described, the same intervention time period of baseline to four weeks was implemented in the current study, thus allowing only pre and posttest measurements.

Grey Cook defines corrective exercises to be designed to address and enhance the relationship between muscle function and fundamental movement by re-training dysfunctional movement patterns, establishing symmetrical movement, and recovering balance posture..$^{3,14,15,18,29,32,47}$ The present study and Bodden et al. ${ }^{29}$ both demonstrated changes within four weeks of a corrective exercises intervention program; while both Cowen et al. ${ }^{35}$ and Goss et al. ${ }^{47}$ reported scores on the FMS can be improved following six week intervention programs. However, even though Cowen et al. ${ }^{35}$ and Goss et al. ${ }^{47}$ interventions demonstrated improvement in FMS score, the training intervention program described can be interpreted not as corrective exercises, but as standard exercises or physical fitness programs. Unlike corrective exercises, fitness programs or standard exercises address and enhance any aspect of physical fitness (i.e., strength, endurance, power, flexibility). The intervention program described in Cowen et al. ${ }^{35}$ was a yoga intervention focusing specifically on breathing, postures, and relaxation. Although yoga can improve certain aspects of functional movement impairments, yoga is described to be a traditional non-competitive, mindful activity that incorporates series of exercises emphasizing the balance between the fitness components of strength and flexibility. ${ }^{35}$ To further differentiate, standard exercises or fitness program can be performance oriented, while corrective exercises are 
preventive oriented and in the case of our study, individualized based on a baseline assessment. Corrective exercise programs are essentially categorized as pre-rehabilitative exercises not fitness programs. For the program intervention described in Goss et al. ${ }^{47}$ the biggest distinguished between physical training versus corrective exercises was the intervention was reported to be 75 minutes in duration, which for most is unconventional and impractical to be categorized as pre-rehabilitative exercises.

Frost et al. ${ }^{22}$ is one of the only studies in which no differences were found between FMS scores in the intervention group when compared to a control group in active firefighters. Frost et al. ${ }^{22}$ examined more than one intervention group; the two intervention groups were described to differ in the emphasis that was placed on movement quality because of the relation to task performance. Therefore, one group was fitness oriented while the other was movement oriented. The mean pre-intervention FMS test scores displayed a mean score of $13.3 \pm 2.5$ for the control, $13.1 \pm 2.7$ for intervention 1 , and $12.8 \pm 1.7$ for intervention 2 . The mean post training FMS scores for the groups was $13.0 \pm 2.4$ for the control, $13.5 \pm 2.3$ for the intervention 1 , and $13.1 \pm$ 1.8 for intervention 2. It is plausible the designs of these interventions are the potential reason for there to be no improvement between the two intervention groups. There is valuable information to be gained from each individual's FMS screen that can and should be used in the development of individualized recommendation for exercises.

Corrective exercises are training programs that target fundamental movement quality and are an essential component of development to allow safe progression. It is recommended by $\mathrm{Cook}^{6}$ for the Functional Movement Screen to be used to individual training programs based on the subject's "weakest link." Although different, the intervention programs described in Bodden et al. ${ }^{29}$ and Kiesel et al. ${ }^{14}$ were designed and followed the exercise algorithm outlined by Cook. ${ }^{6}$ 
This algorithm uses specific corrective exercises performed that target movement pattern limitations related to the seven FMS tasks. The intervention program implanted by Bodden et al. ${ }^{29}$ was not individualized but was designed to focus on the weakest and asymmetrical scores, as its primary focus was on mobility patterns and secondary moved onto stability patterns when it was demonstrated to be appropriate. In Kiesel et al. ${ }^{14}$ the intervention was used to transfer the gained mobility into enhanced motor learning; as the corrective exercises were individualized and designed to stimulate neutral core muscle activation to enhance the relationship between core muscle function and fundamental movement. The intervention program within the present study shared this concept by using the FMS Pro360 program, a computerized software which shares similar fundamental value recommended by Cook. At this point in the literature, this is the first controlled trial using the FMS Pro360 program and have shown improvements. The FMS Pro360 program was utilized in the following study in an effort to design individualized programs that provided the most benefit for each active ROTC cadet. For the majority of the programs, the corrective exercises assigned to the participants focused on basic level with an emphasis on proper form for all movement patterns (i.e. mobility and stability).

In addition to examining the effectiveness of corrective exercises, a unique aspect of this research was its studying the association between functional movement patterns and physical fitness. Currently, the literature attempting to link FMS scores and physical performance are unclear. ${ }^{2,32-34,42-44}$ The results of this study disagree with the original hypothesis as there was non-significant correlation between the two measurements. These results are similar and consistent findings as found within the existing literature. ${ }^{34,43,44}$ Girard et al. ${ }^{34}$ conducted a systematic review to examine if FMS correlates with enhanced athletic performance, but interesting found that in most of the included studies there was not a significant correlation 
between composite FMS scores and athletic performance. Our findings further support these previous investigations.

For this current study, the performance variable was associated to the military population, similar to a study conducted by Lisman et al. ${ }^{8}$. Lisman et al. ${ }^{8}$ examined the association between FMS scores and the Physical Fitness Test (PFT). Unlike the APFT, the PFT is the standardized Marine Corps performance test and consisted of the completion of number of pull-ups until exhaustion (PUE), timed abdominal crunches (AC), and 3-mile run time (RT). Interestingly, in contrast to the current research, some of the PFT performance scores and FMS test components demonstrated to be positively correlated. The PUE test was the only PFT test associated with total FMS score $(\mathrm{p}<0.01, \mathrm{r}=0.12)$ as it demonstrated to be positively correlated with the squat $(\mathrm{p}<0.01, \mathrm{r}=0.10)$, lunge $(\mathrm{p}<0.01, \mathrm{r}=0.11), \operatorname{ASLR}(\mathrm{p}<0.05, \mathrm{r}=0.07)$, and STPU $(\mathrm{p}<0.01, \mathrm{r}=0.09)$. In addition, the $\mathrm{AC}$ performance was also positively related to both the squat $(\mathrm{p}<0.05, \mathrm{r}=0.07$ ) and lunge $(\mathrm{p}<0.001, \mathrm{r}=0.15){ }^{8}$

One interesting difference between our study and previous investigations on corrective exercises were the mean pre-intervention FMS scores. According to Minthorn et al. ${ }^{15}$ the baseline FMS scores between professional football players ${ }^{14}$, active firefighters ${ }^{22}$, and mix martial art athletes ${ }^{14,22,29}$ were similar for all groups (lowest $12.8 \pm 1.7$, highest $13.3 \pm 1.9$ ) except football linemen $(11.8 \pm 1.8)$, with no significant differences between control and intervention groups. ${ }^{15}$ Interestingly, these results are dissimilar to those found in this current study, as the baseline FMS scores in the present study were reportedly higher. The subjects in the current study had a pre mean FMS score of $15.3 \pm 2.30$. Between these studies and the present study, the difference of baseline FMS scores could be based on the dissimilarity between the populations; as younger healthy, physically active individuals' scored perhaps higher than 
semiprofessional athletes or active firefighters due to demographics (i.e. age) and training regimen differences.

\section{Limitations}

This study had several limitations. First due to the procedures of the study, participants and the examiner were not blinded to the pre intervention data and it is possible they remembered what they scored previously and that could have affected the post-test, however this was minimized by averting any feedback on test instruction and scoring to participants. Second, it should be noted all participants in the current study were healthy, physically active individuals enrolled in their local University ROTC program. All participants were collegiate aged, which may limit the generalizability of the findings. Further study is required to determine the effectiveness of individual corrective exercises in individuals with a FMS score equal to or less than 14. Finally, we observed a difference between APFT scores within the control and experimental group. This could have created a ceiling effect in which the independent variable of corrective exercises had a minor influence or no effect on the dependent variable of APFT scores. In addition, anecdotal comments of improvement were noted and although it was encouraging to see improvement in subjective measures of physical performance, results were not statistically significant. 


\section{CHAPTER V: CONCULSION}

\section{Conclusions and Implications}

To our knowledge this is the first study to observe changes in functional movement from a corrective exercise in addition to observing its changes on performance. In conclusion, the results of this study indicate a weak correlation between FMS and physical fitness performance. The results demonstrated individualized corrective exercises improved FMS scores, but fail to improve physical fitness performance, like the APFT. The results from this study show the benefits of prescreening individuals for musculoskeletal dysfunction and further support the utilization of correcting the dysfunction.

At this point in the literature, this is the first controlled trial using the FMS Pro360 program and have shown improvements, however this study did not include any form of progressing the exercises. Providing progressive corrective exercise programs specific to improving levels of dysfunction or maintaining/enhancing function may further support the effects of corrective exercises. Research should investigate progression of the exercises. There was no progression in the following study; perhaps the changes in scores observed occurred earlier in the program and progressions could have been made to further improve dysfunction. Additional research should focus on examining the change in the FMS as it relates to dosage of a corrective exercise program.

\section{Practical Application}

The FMS provides an opportunity to create individualized training programs that focuses on changing or modifying movement patterns. This study supports the use of corrective exercise interventions. The use of corrective exercises programs, specifically individualized programs can improve movement dysfunction; however based on this study's results the FMS is not a useful 
tool for determining performance capabilities and it can be assumed only physical training programs can improve the fitness. Practicing clinicians should appreciate the value of individualize training programs and seek to enhance physical performance or prevent future injuries. 


\section{TABLES}

Table 1. Descriptive Statistics: Participant Demographics

\begin{tabular}{ccccc}
\hline GROUP & & AGE $($ YEAR $)$ & HEIGHT $(\mathrm{CM})$ & WEIGHT(KG) \\
\hline TOTAL & $\mathrm{N}=44$ & $19.84 \pm 1.48$ & $172.29 \pm 45.20$ & $71.75 \pm 13.52$ \\
\hline CONTROL & $\mathrm{N}=20$ & $19.6 \pm 1.50$ & $168.98 \pm 10.93$ & $68.81 \pm 12.59$ \\
\hline EXPERIMENTAL & $\mathrm{N}=24$ & $20.04 \pm 1.46$ & $174.62 \pm 10.70$ & $74.20 \pm 14.05$
\end{tabular}

Note. Demographics are presented as mean $\pm \mathrm{sd}$

Table 2. Descriptive Statistics: Pre and Post FMS scores

\begin{tabular}{ccccc}
\hline GROUP & & BASELINE & $\begin{array}{c}\text { POST } \\
\text { INTERVENTION }\end{array}$ & CHANGE \\
& & & $15.2 \pm 1.64$ & $-0.6 \pm 1.60$ \\
\hline CONTROL & $\mathrm{N}=20$ & $15.8 \pm 2.04$ & $16.71 \pm 1.97$ & $1.79 \pm 1.74$ \\
\hline
\end{tabular}

Note. Scores are presented as mean $\pm \mathrm{sd}$

Table 3. Descriptive Statistics: Pre and Post APFT scores

\begin{tabular}{ccccc}
\hline GROUP & & BASELINE & $\begin{array}{c}\text { POST } \\
\text { INTERVENTION }\end{array}$ & CHANGE \\
\hline CONTROL & $\mathrm{N}=20$ & $224.8 \pm 48.89$ & $251.9 \pm 39.99$ & $7.1 \pm 17.48$ \\
\hline EXPERIMENTAL & $\mathrm{N}=24$ & $264.75 \pm 34.37$ & $270.21 \pm 26.70$ & $5.46 \pm 16.44$ \\
\hline
\end{tabular}

Note. Scores are presented as mean $\pm \mathrm{sd}$ 


\section{FIGURES}

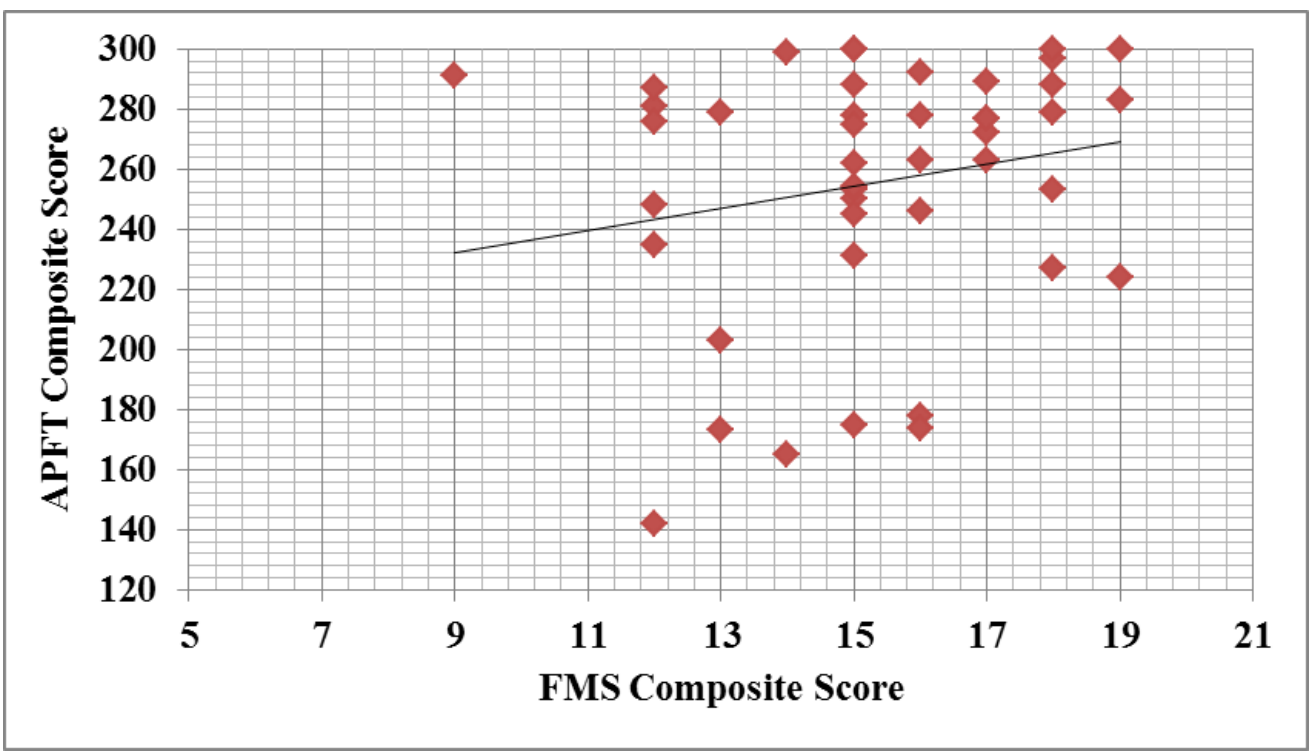

Figure 1. Relationship between the FMS and APFT

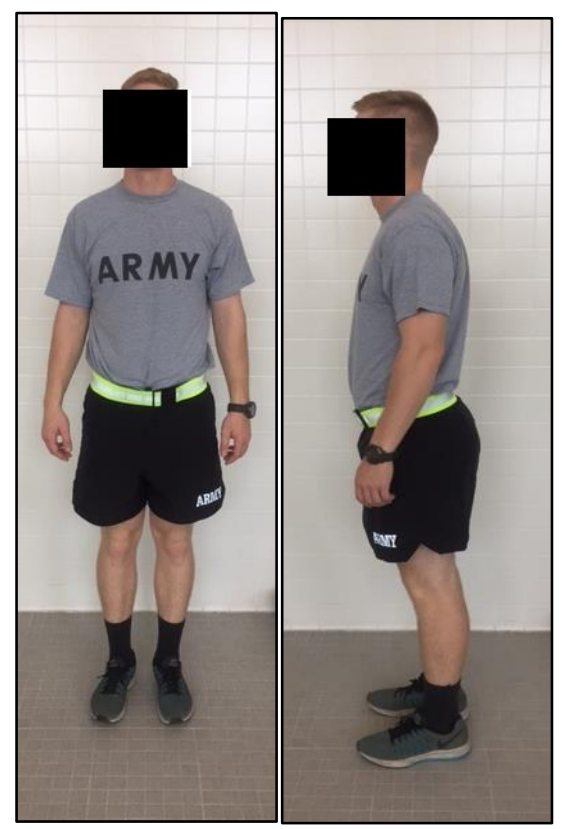

Figure 2. Particpant Apperel: Improved Physical Fitness Uniform 


\section{REFERENCES}

1. Cook G, Burton L, Hoogenboom B. Pre-participation screening: the use of fundamental movements as an assessment of function - part 1. N Am J Sports Phys Ther. 2006;1(2):62-72.

2. Lockie R, Schultz A, Callaghan S, Jordan C, Luczo T, Jeffriess M. A preliminary investigation into the relationship between functional movement screen scores and athletic physical performance in female team sport athletes. Biol Sport. 2015;32(1):41-51.

3. Cook G, Burton L, Hoogenboom BJ, Voight M. Functional movement screening: the use of fundamental movements as an assessment of function - part 1. Int J Sports Phys Ther. 2014;9(3):396-409.

4. Cook G, Burton L, Hoogenboom BJ, Voight M. Functional movement screening: the use of fundamental movements as an assessment of function-part 2. Int J Sports Phys Ther. 2014;9(4):549-563.

5. Cook G, Burton L, Hoogenboom B. Pre-participation screening: the use of fundamental movements as an assessment of function - part 2. N Am J Sports Phys Ther. 2006;1(3):132-139.

6. Cook G. Movement: Functional Movement Systems. Screening-Assessment-Corrective Strategies In: Burton L, Kiesel K, Rose G, Bryant MF, eds. Santa Cruz, California: On target Publications; 2010:408.

7. Knapik JJ, East WB. History of United States Army physical fitness and physical readiness training. US Army Med Dep J. 2014:5-19.

8. Lisman P, O'Connor FG, Deuster PA, Knapik JJ. Functional movement screen and aerobic fitness predict injuries in military training. Med Sci Sports Exerc. 2013;45(4):636-643.

9. Simpson K, Redmond JE, Cohen BS, et al. Quantification of physical activity performed during US Army Basic Combat Training. US Army Med Dep J. 2013:55-65.

10. Thomas DQ, Lumpp SA, Schreiber JA, Keith JA. Physical fitness profile of Army ROTC cadets. J Strength Cond Res. 2004;18(4):904-907.

11. Kiesel K, Plisky PJ, Voight ML. Can Serious Injury in Professional Football be Predicted by a Preseason Functional Movement Screen? N Am J Sports Phys Ther. 2007;2(3):147158.

12. Schneiders AG, Davidsson A, Hörman E, Sullivan SJ. Functional movement screen normative values in a young, active population. Int J Sports Phys Ther. 2011;6(2):75-82. 
13. Bock C, Orr RM. Use of the Functional Movement Screen in a Tactical Population: A Review. April 2015;23:33-42.

14. Kiesel K, Plisky P, Butler R. Functional movement test scores improve following a standardized off-season intervention program in professional football players. Scand $J$ Med Sci Sports. 2011;21(2):287-292.

15. Minthorn LM, Fayson SD, Stobierski LM, Welch CE, Anderson BE. The Functional Movement Screen's Ability to Detect Changes in Movement Patterns After a Training Intervention. J Sport Rehabil. 2015;24(3):322-326.

16. Loudon JK, Parkerson-Mitchell AJ, Hildebrand LD, Teague C. Functional movement screen scores in a group of running athletes. J Strength Cond Res. 2014;28(4):909-913.

17. Agresta C, Slobodinsky M, Tucker C. Functional movement ScreenTM--normative values in healthy distance runners. Int J Sports Med. 2014;35(14):1203-1207.

18. Sprague PA, Mokha GM, Gatens DR. Changes in functional movement screen scores over a season in collegiate soccer and volleyball athletes. J Strength Cond Res. 2014;28(11):3155-3163.

19. Butler RJ, Contreras M, Burton LC, Plisky PJ, Goode A, Kiesel K. Modifiable risk factors predict injuries in firefighters during training academies. Work. 2013;46(1):11-17.

20. Gulgin H, Hoogenboom B. The functional movement screening $(\mathrm{fms})^{\mathrm{TM}}$ : an inter-rater reliability study between raters of varied experience. Int J Sports Phys Ther. 2014;9(1):14-20.

21. Hotta T, Nishiguchi S, Fukutani N, et al. Functional Movement Screen for Predicting Running Injuries in 18- to 24-Year-Old Competitive Male Runners. J Strength Cond Res. 2015;29(10):2808-2815.

22. Frost DM, Beach TA, Callaghan JP, McGill SM. Using the Functional Movement Screen $^{\mathrm{TM}}$ to evaluate the effectiveness of training. J Strength Cond Res. 2012;26(6):16201630 .

23. Frost DM, Beach TA, Callaghan JP, McGill SM. FMS ${ }^{\text {TM }}$ scores change with performers' knowledge of the grading criteria - Are general whole-body movement screens capturing "dysfunction"? J Strength Cond Res. 2013.

24. Onate JA, Dewey T, Kollock RO, et al. Real-time intersession and interrater reliability of the functional movement screen. J Strength Cond Res. 2012;26(2):408-415.

25. Smith CA, Chimera NJ, Wright NJ, Warren M. Interrater and intrarater reliability of the functional movement screen. J Strength Cond Res. 2013;27(4):982-987. 
26. Teyhen DS, Shaffer SW, Lorenson CL, et al. The Functional Movement Screen: a reliability study. J Orthop Sports Phys Ther. 2012;42(6):530-540.

27. Shultz R, Anderson SC, Matheson GO, Marcello B, Besier T. Test-retest and interrater reliability of the functional movement screen. J Athl Train. 2013;48(3):331-336.

28. Stobierski LM, Fayson SD, Minthorn LM, Valovich McLeod TC, Welch CE. Reliability of clinician scoring of the functional movement screen to assess movement patterns. $J$ Sport Rehabil. 2015;24(2):219-222.

29. Bodden JG, Needham RA, Chockalingam N. The effect of an intervention program on functional movement screen test scores in mixed martial arts athletes. J Strength Cond Res. 2015;29(1):219-225.

30. Scott SA, Simon JE, Van Der Pol B, Docherty CL. Risk Factors for Sustaining a Lower Extremity Injury in an Army Reserve Officer Training Corps Cadet Population. Mil Med. 2015;180(8):910-916.

31. Government US. Field Manual (FM) 7-22 Army Physical Readiness Training. In: Headquarters, ed. Washington, D.C.: U.S. Government Printing Office (GPO); 2012:434.

32. Kraus K, Schütz E, Taylor WR, Doyscher R. Efficacy of the functional movement screen: a review. J Strength Cond Res. 2014;28(12):3571-3584.

33. Okada T, Huxel KC, Nesser TW. Relationship between core stability, functional movement, and performance. J Strength Cond Res. 2011;25(1):252-261.

34. Girard J, Quigley M, Helfst F. Does the functional movement screen correlate with athletic performance? A systematic review. Physical Therapy Reviews. 2016;21(2):83-90.

35. Cowen VS. Functional fitness improvements after a worksite-based yoga initiative. $J$ Bodyw Mov Ther. 2010;14(1):50-54.

36. Cook G. Movement. California: On Target Publications; 2010.

37. Butler RJ, Plisky PJ, Southers C, Scoma C, Kiesel KB. Biomechanical analysis of the different classifications of the Functional Movement Screen deep squat test. Sports Biomech. 2010;9(4):270-279.

38. Abraham A, Sannasi R, Nair R. Normative values for the functional movement screentm in adolescent school aged children. Int J Sports Phys Ther. 2015;10(1):29-36.

39. Bardenett SM, Micca JJ, DeNoyelles JT, Miller SD, Jenk DT, Brooks GS. FUNCTIONAL MOVEMENT SCREEN NORMATIVE VALUES AND VALIDITY IN HIGH SCHOOL ATHLETES: CAN THE FMS ${ }^{\text {TM }}$ BE USED AS A PREDICTOR OF INJURY? Int J Sports Phys Ther. 2015;10(3):303-308. 
40. Chimera NJ, Smith CA, Warren M. Injury history, sex, and performance on the functional movement screen and Y balance test. J Athl Train. 2015;50(5):475-485.

41. Kiesel KB, Butler RJ, Plisky PJ. Prediction of injury by limited and asymmetrical fundamental movement patterns in american football players. J Sport Rehabil. 2014;23(2):88-94.

42. Lockie RG, Schultz AB, Jordan CA, Callaghan SJ, Jeffriess MD, Luczo TM. Can selected functional movement screen assessments be used to identify movement deficiencies that could affect multidirectional speed and jump performance? J Strength Cond Res. 2015;29(1):195-205.

43. Chapman RF, Laymon AS, Arnold T. Functional movement scores and longitudinal performance outcomes in elite track and field athletes. Int J Sports Physiol Perform. 2014;9(2):203-211.

44. Parchman CJ, McBride JM. Relationship between functional movement screen and athletic performance. In. Vol 25: Journal Of Strength \& Conditioning Research (Lippincott Williams \& Wilkins)Journal Of Strength \&amp; Conditioning Research (Lippincott Williams \&amp; Wilkins); 2011:3378-3384.

45. Linek P, Saulicz E, Myśliwiec A, Wójtowicz M, Wolny T. The Effect of Specific Sling Exercises on the Functional Movement Screen Score in Adolescent Volleyball Players: A Preliminary Study. J Hum Kinet. 2016;54:83-90.

46. Wright MD, Portas MD, Evans VJ, Weston M. The effectiveness of 4 weeks of fundamental movement training on functional movement screen and physiological performance in physically active children. J Strength Cond Res. 2015;29(1):254-261.

47. Goss DL, Christopher GE, Faulk RT, Moore J. Functional training program bridges rehabilitation and return to duty. J Spec Oper Med. 2009;9(2):29-48.

48. Government US. Wear and Appearance of Army Uniforms and Insignia. 2015. 
APPENDIX A: FUNCTIONAL MOVEMENT SCREEN SCORING CRITERIA

\begin{tabular}{|c|c|c|c|}
\hline $\begin{array}{l}\text { MOVEMENT } \\
\text { PATTERN }\end{array}$ & 3 & 2 & 1 \\
\hline DEEP SQUAT & $\begin{array}{l}\text { Upper torso is parallel } \\
\text { with tibia or toward } \\
\text { vertical. Femur below } \\
\text { horizontal. Knees are } \\
\text { aligned over feet. Dowel } \\
\text { over feet }\end{array}$ & $\begin{array}{l}\text { Upper torso is parallel } \\
\text { with tibia or toward } \\
\text { vertical. Femur is } \\
\text { below horizontal. } \\
\text { Knees are aligned over } \\
\text { feet. Dowel is aligned } \\
\text { over feet. Heels are } \\
\text { elevated }\end{array}$ & $\begin{array}{l}\text { Tibia and upper } \\
\text { torso are not } \\
\text { parallel. Femur is } \\
\text { not below } \\
\text { horizontal. Knees } \\
\text { are not aligned } \\
\text { over feet. Lumbar } \\
\text { flexion is noted. } \\
\text { Heels are elevated }\end{array}$ \\
\hline HURDLE STEP & $\begin{array}{l}\text { Hips, knees, and ankles } \\
\text { remain aligned in the } \\
\text { sagittal plane. Minimal } \\
\text { to no movement is noted } \\
\text { in lumbar spine. Dowel } \\
\text { and hurdle remain } \\
\text { parallel }\end{array}$ & $\begin{array}{l}\text { Alignment is lost } \\
\text { between hips, knees, } \\
\text { and ankles. } \\
\text { Movement is noted in } \\
\text { lumbar spine. Dowel } \\
\text { and hurdle do not } \\
\text { remain parallel }\end{array}$ & $\begin{array}{l}\text { Contact between } \\
\text { foot and hurdle } \\
\text { occurs. Loss of } \\
\text { balance is noted }\end{array}$ \\
\hline IN LINE LUNGE & $\begin{array}{l}\text { Dowel contacts } \\
\text { maintained. Dowel } \\
\text { remains vertical. No } \\
\text { torso movement noted. } \\
\text { Dowel and feet remain } \\
\text { in sagittal plan. Knee } \\
\text { touches board behind } \\
\text { heel of front foot }\end{array}$ & $\begin{array}{l}\text { Dowel contact not } \\
\text { maintained. Dowel } \\
\text { does not remain } \\
\text { vertical. Movement } \\
\text { noted in torso. Dowel } \\
\text { and feet do not remain } \\
\text { in sagittal plane. Knee } \\
\text { does not touch behind } \\
\text { heel of front foot }\end{array}$ & $\begin{array}{l}\text { Loss of balance is } \\
\text { noted }\end{array}$ \\
\hline $\begin{array}{l}\text { SHOULDER } \\
\text { MOBILITY }\end{array}$ & $\begin{array}{l}\text { Fists are within one } \\
\text { hand length }\end{array}$ & $\begin{array}{l}\text { Fists are within one- } \\
\text { and-a-half hand } \\
\text { lengths }\end{array}$ & $\begin{array}{l}\text { Fists are not within } \\
\text { one and half hand } \\
\text { lengths }\end{array}$ \\
\hline $\begin{array}{l}\text { ACTIVE STRAIGHT } \\
\text { LEG RAISE }\end{array}$ & $\begin{array}{l}\text { Vertical line of the } \\
\text { malleolus resides } \\
\text { between mid-thigh and } \\
\text { ASIS. The non-moving } \\
\text { limb remains in neutral } \\
\text { position }\end{array}$ & $\begin{array}{l}\text { Vertical line of the } \\
\text { malleolus resides } \\
\text { between mid-thigh } \\
\text { and joint line. The } \\
\text { non-moving limb } \\
\text { remains in neutral } \\
\text { position }\end{array}$ & $\begin{array}{l}\text { Vertical line of the } \\
\text { malleolus resides } \\
\text { below joint line. } \\
\text { The non-moving } \\
\text { limb remains in } \\
\text { neutral position }\end{array}$ \\
\hline
\end{tabular}


TRUNK STABILITY PUSH UP

ROTARTY STABILITY
The body lifts as a unit with no lag in the spine. Men perform a repetition with thumbs aligned with the top of the head. Women perform a repetition with thumbs aligned with the chin
The body lifts as a unit with no lag in the spine. Men perform a repetition with thumbs aligned with the chin. Women with thumbs aligned with clavicle

Performs a correct diagonal repetition
Men are unable to perform a repetition with hands aligned with the chin.

Women unable with thumbs aligned with the clavicle
Performs a correct unilateral repetition
Inability to perform a diagonal repetition 


\section{APPENDIX B: VERBAL INSTRUCTIONS FOR FUNCTIONAL MOVMENT SCREEN}

The following is a script to use while administering the FMS. For consistency throughout all screens, this script should be used during each screen. The bold words represent what you should say to the client. Please let me know if there is any pain while performing any of the following movements.

\section{DEEP SQUAT:}

- Stand tall with your feet approximately shoulder width apart and toes pointing forward.

- Grasp the dowel in both hands and place it horizontally on top of your head so your shoulders and elbows are at 90 degrees.

- Press the dowel so that it is directly above your head.

- While maintaining an upright torso, and keeping your heels and the dowel in position, descend as deep as possible.

- Hold the descended position for a count of one, then return to the starting position.

- Do you understand the instructions?

Score the movement. The client can perform the move up to three times total if necessary. If a score of three is not achieved, repeat above instructions using the 2 x 6 under the client's heels.

\section{HURDLE STEP:}

- Stand tall with your feet together and toes touching the test kit.

- Grasp the dowel with both hands and place it behind your neck and across the shoulders.

- While maintaining an upright posture, raise the right leg and step over the hurdle, making sure to raise the foot towards the shin and maintaining foot alignment with the ankle, knee and hip.

- Touch the floor with the heel and return to the starting position while maintaining foot alignment with the ankle, knee and hip.

- Do you understand these instructions?

Score the moving leg. Repeat the test on the other side. Repeat two times per side if necessary.

\section{INLINE LUNGE:}

- Place the dowel along the spine so it touches the back of your head, your upper back and the middle of the buttocks.

- While grasping the dowel, your right hand should be against the back of your neck, and the left hand should be against your lower back.

- Step onto the 2x6 with a flat right foot and your toe on the zero mark.

- The left heel should be placed at mark. This is the tibial measurement marker.

- Both toes must be pointing forward, with feet flat.

- Maintaining an upright posture so the dowel stays in contact with your head, upper back and top of the buttocks descend into a lunge position so the right knee touches the $2 \times 6$ behind your left heel. 
- Return to the starting position.

- Do you understand these instructions?

Score the movement. Repeat the test on the other side. Repeat two times per side if necessary.

SHOULDER MOBILITY:

- Stand tall with your feet together and arms hanging comfortably.

- Make a fist so your fingers are around your thumbs.

- In one motion, place the right fist overhead and down your back as far as possible while simultaneously taking your left fist up your back as far as possible.

- Do not "creep" your hands closer after their initial placement.

- Do you understand these instructions?

Measure the distance between the two closest points of each fist. Score the movement. Repeat the test on the other side.

ACTIVE SCAPUALR STABILITY (SHOULDER CLEARING)

- Stand tall with your feet together and arms hanging comfortably.

- Place your right palm on the front of your left shoulder.

- While maintaining palm placement, raise your right elbow as high as possible.

- Do you feel any pain?

Repeat the test on the other side.

ACTIVE STRAIGHT LEG RAISE:

- Lay flat with the back of your knees against the 2x6 with your toes pointing up.

- Place both arms next to your body with the palms facing up.

- Pull the toes of your right foot toward your shin.

- With the right leg remaining straight and the back of your left knee maintaining contact with the $2 \times 6$, raise your right foot as high as possible.

- Do you understand these instructions?

Score the movement. Repeat the test on the other side.

TRUNK STBAILITY PUSH UP:

- Lie face down with your arms extended overhead and your hands shoulder width apart.

- Pull your thumbs down in line with the (forehead for men, chin for women).

- With your legs together, pull your toes toward the shins and lift your knees and elbows off the ground.

- While maintaining a rigid torso, push your body as one unit into a pushup position.

- Do you understand these instructions?

Score the movement. Repeat two times if necessary. Repeat the instructions with appropriate hand placement if necessary. 


\section{SPINAL EXTENSION CLEARING}

- While lying on your stomach, place your hands, palms down, under your shoulders.

- With no lower body movement, press your chest off the surface as much as possible by straightening your elbows.

- Do you understand these instructions?

- Do you feel any pain?

ROTARY STABILITY:

- Get on your hands and knees over the 2x6 so your hands are under your shoulders and your knees are under your hips.

- The thumbs, knees and toes must contact the sides of the $2 \times 6$, and the toes must be pulled toward the shins.

- At the same time, reach your right hand forward and right leg backward, like you are flying.

- Then without touching down, touch your right elbow to your right knee directly over the $2 \times 6$.

- Return to the extended position.

- Return to the start position.

- Do you understand these instructions?

Score the movement. Repeat the test on the other side. If necessary, instruct the client to use a diagonal pattern of right arm and left leg. Repeat the diagonal pattern with left arm and right leg. Score the movement.

SPINAL FLEXION CLEARING

- Get on all fours, and rock your hips toward your heels.

- Lower your chest to your knees, and reach your hands in front of your body as far as possible.

- Do you understand these instructions?

- Do you feel any pain? 